\title{
CXCR1 promotes malignant behavior of gastric cancer cells in vitro and in vivo in AKT and ERK1/2 phosphorylation
}

\author{
JUNPU WANG $^{1,2}$, WANMING HU ${ }^{2,4}$, XIAOYING WU ${ }^{1,2}$, KUANSONG WANG $^{1,2}$, JUN YU $^{3}$, \\ BAIHUA LUO ${ }^{1,2}$, GENGQIU LUO ${ }^{1,2}$, WEIYUAN WANG ${ }^{2}$, HUILING WANG $^{2}$, JINGHE LI $^{1,2}$ and JIFANG WEN ${ }^{1,2}$ \\ ${ }^{1}$ Department of Pathology, Xiang-ya Hospital, ${ }^{2}$ Department of Pathology, School of Basic Medicine, Central South University, \\ ${ }^{3}$ Department of Neurology, Third Xiang-ya Hospital, Central South University, Changsha, Hunan 410083; \\ ${ }^{4}$ Department of Pathology, Sun Yat-sen University Cancer Center, Guangzhou 510060, P.R. China
}

Received January 28, 2016; Accepted February 24, 2016

DOI: $10.3892 /$ ijo.2016.3428

\begin{abstract}
CXCR1 is a member of the chemokine receptor family, which was reported to play an important role in several cancers. The present study investigated the influence of CXCR1 stable knockdown or overexpression on the malignant behavior of gastric cancer cells in vitro and in vivo and the potential mechanisms. MKN45 and BGC823 cells were stably transfected with plasmid pYr-1.1-CXCR1-shRNA (knockdown) and pIRES2-ZsGreen1-CXCR1 (overexpression), respectively. Malignant behavior was evaluated in vitro for changes in proliferation by MTT and colony forming assays; cell cycle and apoptosis by flow cytometry; and migration and invasion using transwell and wound-healing assays. Proliferation, cell cycle, apoptosis, migration and invasion-related signaling molecule expression were measured by real-time RT-PCR and western blot analysis. CXCR 1 knockdown and overexpressing xenografts were monitored for in vivo tumor growth. Stable knockdown of CXCR1 inhibited MKN45 cell proliferation, migration and invasion, but were reversed in BGC823 cells stably overexpressing CXCR1. In addition, MKN45 cells stably transfected with CXCR1 shRNA inhibited AKT and ERK1/2 phosphorylation, protein expression of cyclin D1, EGFR, VEGF, MMP-9, MMP-2 and Bcl-2, and increased protein expression of Bax and E-cadherin (all $\mathrm{P}<0.05)$. In vivo CXCR1-shRNA-MKN45 cells transplanted into nude mice formed smaller tumors than non-transfected or scrambled-shRNA cells (both $\mathrm{P}<0.05$ ). In contrast BGC823 cells overexpressing CXCR1 formed larger tumors in mice than cells carrying an empty expression plasmid or nontransfected cells (both $\mathrm{P}<0.05$ ). CXCR1 promoted gastric cancer cell proliferation, migration and invasion. The present
\end{abstract}

Correspondence to: Dr Jinghe Li, Department of Pathology, Xiang-ya Hospital, Central South University, Changsha, Hunan 410083, P.R. China

E-mail: jingheli159@sina.com

Key words: CXCR1, gastric cancer, proliferation, migration, invasion, AKT phosphorylation study provides preclinical data to support CXCR1 as a novel therapeutic target for gastric cancer.

\section{Introduction}

Gastric cancer was the fourth most common malignancy in the world in 2008 with approximately one million new cases (1). Although gastric cancer incidence has steadily declined by more than $80 \%$ over the past 50 years in most developed countries, such as North America and Europe (1-3), gastric cancer is one of the most significant health problems in developing countries. If diagnosed in the early-stage, $90 \%$ of gastric cancer patients can survive for more than 5 years after surgery (2), while the survival rate is dramatically reduced for patients with local recurrent and metastasized disease (3). Currently, most gastric cancer patients are diagnosed in the advanced stages of disease, which contribute to the high rate of gastric cancer lethality in China as well as in most other developing countries (4). Thus, novel strategies in prevention, early diagnosis, and effective control of gastric cancer progression is urgently needed. To this end, better understanding of the molecular mechanisms of gastric cancer development and progression could provide insightful information to develop novel approaches for gastric cancer treatment.

Chemokines are a family of small proteins $(8-11 \mathrm{kDa})$ that are divided into four groups according to the number and spacing of the first two cysteine residues in their aminoterminal end $(\mathrm{C}, \mathrm{CC}, \mathrm{CXC}$ and $\mathrm{CX} 3 \mathrm{C})(5,6)$. They represent a large family of polypeptide signaling molecules, originally characterized by their ability to promote the directed chemotaxis of leukocytes, and are known to play important roles in inflammation and cancer (7). Of these chemokines, CXC chemokines can be further subdivided into two groups on the basis of presence or absence of an ELR motif (glutamic acid, leucine and arginine) which precedes the first cysteine residues in the protein. These CXC chemokines have been implicated in the initiation and amplification of inflammatory diseases (8). CXC chemokines are known to bind to G-protein-coupled receptors (GPCR) mainly CXCR1 and CXCR2 which plays an important role in cancer progression and metastasis (9). Many studies have shown that chemokine receptor CXCR1/2 and their ligands played an important regulatory role in the occur- 
rence, proliferation, growth, invasion, metastasis, angiogenesis and drug resistance of various tumors (10), such as malignant melanoma (11), breast (12), pancreatic (13), colon (14) and ovarian cancer (15).

CXCR1 is a cell surface receptor of interleukin-8 (IL-8 called CXCL8) $(16,17)$. This molecule is shown to be upregulated and associated with poor prognosis of gastric cancer (18). Specifically, CXCR1 is a class A, rhodopsin-like G proteincoupled receptor, the largest class of integral membrane proteins responsible for cellular signal transduction and targeted as drug receptors (19). Despite the potential importance in cells, the molecular mechanism of CXCR1 signal transduction is poorly understood due to the limited structural information available (19). Furthermore, the role and mechanism of CXCR1 in gastric cancer are still unclear. Thus, in the present study, we aimed to detect the influence of CXCR1 stable knockdown or overexpression on the gastric cancer cell proliferation, migration and invasion, and the protein expression related to the proliferation, growth, apoptosis (Bcl-2, Bax, cyclin D1, EGFR and Ki-67), angiogenesis (VEGF), invasion and metastasis (MMP-9, MMP-2 and E-cadherin) and the phosphorylation of AKT and ERK1/2 before and after the silencing of CXCR1.

\section{Materials and methods}

Cell culture. Gastric cancer cell lines MKN45 and BGC823 were obtained from the Type Culture Collection of Chinese Academy of Sciences (Shanghai, China). The cells were cultured with Dulbecco's modified Eagle's medium (DMEM; Gibco-BRL, Life Technologies, Gaithersburg, MD, USA) containing 10\% fetal bovine serum (FBS; Gibco-BRL) and $1 \%$ penicillin/streptomycin (Invitrogen, Carlsbad, CA, USA) at $37^{\circ} \mathrm{C}$ in $5 \% \mathrm{CO}_{2}$ atmosphere.

CXCR1 RNA interference and stable lines. RNA interference (RNAi) specific for CXCR1 were designed with GenScript software (https://www.genscript.com/ssl-bin/app/RNAi, GenScript, USA) using the human CXCR1 mRNA sequence (GenBank registration number: NM_000634. 2). Three sequences were identified as specific CXCR1-shRNA targeted sequences and confirmed by the homologous analysis using the BLAST algorithm. In addition, scrambled shRNA sequence was designed, which did not target specific gene coding regions. Primers were synthesized by Invitrogen (Shanghai, China).

CXCR1 shRNA and scramble shRNA sequence were cloned into the pYr 1.1 plasmid vector (Yingrun Biotechnologies, Inc., Changsha, China). This vector contains human U6 promoter, encoded green fluorescent protein (GFP) report gene, kanamycin resistance gene as a marker in prokaryotic screening and neomycin resistance gene as a marker in eukaryotic screening. MKN45 cells at $90-95 \%$ confluence were transiently transfected using Lipofectamine ${ }^{\mathrm{TM}} 2000$ (Invitrogen) with plasmids pYr-1.1-CXCR1-shRNA-1, pYr-1.1-CXCR1-shRNA-2, pYr1.1-CXCR1-shRNA-3 and pYr-1.1-scramble-shRNA. After a 48-h culture in complete medium, cells were further incubated in a conditioned medium contained G418 $(800 \mu \mathrm{g} / \mathrm{ml})$ for one month to select positive clones. Finally, cells were screened and cultured in medium with $400 \mu \mathrm{g} / \mathrm{ml}$ of G418 to establish the stable transfected cell lines (CXCR1-shRNA-MKN45 and scramble-shRNA-MKN45). The positive clones were analyzed by real-time RT-PCR and western blot analysis.

CXCR1 overexpression and stable lines. The 5'-GAGACACT CAACAAGTATGTT-3' (mature sense for CXCR1-shRNA-3) sequence was inserted into the plasmid pIRES2-ZsGreen1. The CXCR1 overexpression plasmid, pIRES2-ZsGreen1CXCR1, was purchased from Yingrun Biotechnologies. Plasmid pIRES2-ZsGreen1 also contained the kanamycin and neomycin resistance genes. BGC823 cells at 90-95\% confluence were transiently transfected using Lipofectamine 2000 with the plasmids pIRES2-ZsGreen1-CXCR1 and pIRES2ZsGreen1. After a 48-h culture in complete medium, cells were further incubated in a conditioned medium containing $\mathrm{G} 418(800 \mu \mathrm{g} / \mathrm{ml})$ for one month to select positive clones. Finally, cells were screened and cultured in medium with $40 \mu \mathrm{g} / \mathrm{ml}$ of $\mathrm{G} 418$ to establish the stable transfected cell lines [pIRES2-ZsGreen1-CXCR1-BGC823 (CXCR1-BGC823) and pIRES2-ZsGreen1-BGC823 (vacant-BGC823)]. The positive clones were analyzed by real-time RT-PCR and western blot analysis.

CXCRI RNAi rescue experiment. To verify that the knockdown of CXCR1 expression by RNAi was efficient and that there were no off-target effects, we constructed a vector containing a mutated CXCR1 gene (pIRES2-ZsGreen1-CXCR1-Mut). Sitedirected mutagenesis was used to alter three bases (underline) in the CXCR1-shRNA-3 target sequence. The sequence before the mutation was 5'-GAG ACA $\underline{\mathrm{C} T} \underline{\mathrm{C}} \mathrm{AA} \underline{\mathrm{C}} \mathrm{AAG}$ TAT GTT-3, and the sequence after the mutation was 5'-GAG ACA TTG AAT AAG TAT GTT-3'. Two primers were synthesized as follows: CXCR1-Mut-forward: 5'-GTATGCTAGAAACT GAGACATTGAATAAGTATGTTGTGATCATCGC-3'. CXCR1-Mut-rerverse: 5'-GCGATGATCACAACATACTT ATTCAATGTCTCAGTTTCTAGCATAC-3'. The mutation sequence was inserted into plasmid pIRES2-ZsGreen1. pIRES2-ZsGreen1-CXCR1-Mut was sequenced and identified by Invitrogen. pYr-1.1-CXCR1-shRNA-3 and pIRES2ZsGreen1-CXCR1-mut were both transfected into MKN45 cells, and the expression of CXCR1 was detected by western blot analysis.

MTT (3-(4,5-dimethylthiazol-2-yl)-2,5-diphenyltetrazolium bromide) cell proliferation assay. Stably transfected cells were seeded into 96-well plates at a density of 5,000 cells/well. MTT solution $(20 \mu \mathrm{l})(5 \mathrm{mg} / \mathrm{ml}$; Sigma Aldrich, St. Louis, MO, USA) was added after 24, 48 and $72 \mathrm{~h}$. The culture was terminated $4 \mathrm{~h}$ of addition MMT solution, and the supernatant in each well was carefully aspirated and discarded. DMSO $(150 \mu \mathrm{l})$ was added into each well, and the plate was rotated for $10 \mathrm{~min}$ at room temperature. Absorbance was measured at $568 \mathrm{~nm}$ using a microplate reader (Bio-Rad Laboratories, Hercules, CA, USA).

Colony forming assay. Stable transfected cells were seeded into 6-well culture plates (200 cells/well) and cultured for 2 to 3 weeks at $37^{\circ} \mathrm{C}$ in a $5 \% \mathrm{CO}_{2}$ incubator. The medium was changed every 3 days. At the end of the experiment, cells were fixed for $15 \mathrm{~min}$ with methanol, stained for $25 \mathrm{~min}$ with 
Table I. Primer sequences for RT-PCR or real-time RT-PCR.

\begin{tabular}{lllc}
\hline Gene & \multicolumn{1}{c}{ Forward primer sequence } & \multicolumn{1}{c}{ Reverse primer sequence } & Product length (bp) \\
\hline$\beta$-actin & 5'-TGACGTGGACATCCGCAAAG-3' & 5'-CTGGAAGGTGGACAGCGAGG-3' & 205 \\
GAPDH & 5'-TGAACGGGAAGCTCACTGG-3' & 5'-TCCACCACCCTGTTGCTGTA-3' & 307 \\
Bax & 5'-CCCGAGAGGTCTTTTTCCGAG-3' & 5'-CCAGCCCATGATGGTTCTGAT-3' & 155 \\
Bcl-2 & 5'-CCTGGGCAATTCCGCATT-3' & 5'-AACAGGCCACGTAAAGCAAC-3' & 158 \\
Cyclin D1 & 5'-GCTGCGAAGTGGAAACCATC-3' & 5'-CCTCCTTCTGCACACATTTGAA-3' & 135 \\
EGFR & 5'-AGGCACGAGTAACAAGCTCAC-3' & 5'-ATGAGGACATAACCAGCCACC-3' & 177 \\
VEGF & 5'-ATTATGCGGATCAAACCTC-3' & 5'-ATTTCTTGCGCTTTCGTT-3' & 157 \\
MMP-9 & 5'-ACTACTGTGCCTTTGAGTCC-3' & 5'-AGAATCGCCAGTACTTCCCA-3' & 115 \\
MMP-2 & 5'-ACTCTGGACTTAGACCGCTTG-3' & 5'-ACAGGTTGCAGCTCTCCTTG-3' & 217 \\
E-cadherin & 5'-GCTAACGTCGTAATCACCAC-3' & 5'-AATGCCATCGTTGTTCACTG-3' & 141 \\
Ki-67 & 5'-AGAAGACCTGCTACTCCAAAGA-3' & 5'-AGTTTGCGTGGCCTGTACTAA-3' & 70 \\
\hline
\end{tabular}

crystal violet, and the number of clones was counted. Cloning efficiency $=($ colonies formed/cells seeded $) \times 100 \%$.

Cell cycle and apoptosis assay. Stable transfected cells were collected by centrifugation and washed twice with ice-cold PBS. Cells were then fixed with $70 \%$ cold ethanol overnight at $4^{\circ} \mathrm{C}$. The next day, cells were collected by centrifugation and washed with PBS before incubation in $500 \mu 1$ of PBS containing $50 \mu \mathrm{g} / \mathrm{ml}$ of propidium iodide (PI; Sigma), $100 \mu \mathrm{g} / \mathrm{ml}$ of RNase A and $0.2 \%$ Triton X-100 in the dark for $30 \mathrm{~min}$ at $4^{\circ} \mathrm{C}$. Flow cytometric analysis was performed using a flow cytometry system and ModFit software (BD Biosciences, San Jose, CA, USA). The proportion of cells in the G0/G1, S, $\mathrm{G} 2 / \mathrm{M}$ phases of the cell cycle was obtained. Sub-G1 indicated cells that were undergoing apoptosis.

Cell migration and invasion assays. In vitro cell migration and invasion experiments were performed using Transwell inserts (Corning Costar, Corning, NY, USA) with the polycarbonate membranes ( $8 \mu \mathrm{m}$ pore size) in 24 -well plates. For the invasion assay, the filter was coated with $20 \mu \mathrm{g} / \mathrm{ml}$ of Matrigel (BectonDickinson) overnight at $4^{\circ} \mathrm{C}$. Stable transfected cells $(100 \mu \mathrm{l})$ at a concentration of $1.0 \times 10^{5} / \mathrm{ml}$ in serum-free medium were seeded into the upper chamber, and $800 \mu \mathrm{l}$ of culture medium containing $10 \%$ FBS was placed in the lower chamber. After a 12-h incubation at $37^{\circ} \mathrm{C}$ with $5 \% \mathrm{CO}_{2}$, non-invaded cells were removed from the upper surface of the membrane by gently scraping with a cotton swab, and the invading cells on the lower surface of the membrane were fixed with methanol, stained with crystal violet solution, rinsed with water and air-dried. The invading cells were viewed under an inverted microscope (Olympus, Tokyo, Japan) and ten fields (magnification, x200) photographed and counted. The same experimental conditions were used for the migration assay with the exception that the chambers were not coated with Matrigel.

Wound-healing assay. Stable transfected cells were seeded into 6-well plates at a density of $1 \times 10^{5} /$ well and cultured until a confluent monolayer formed. The tip of a $200-\mu 1$ pipette was then used to draw a wound at the bottom of each well. The cells were washed with PBS and then further cultured for 24, 48 and $72 \mathrm{~h}$. The wounded areas were photographed at x10 magnification using computer-assisted microscopy (Olympus IX70; Olympus). Images were captured at 0, 24, 48 and $72 \mathrm{~h}$ after the scratch was made. The distance cells migrated was measured and analyzed using CellProfiler 2.0 cell image analysis software (http://www.cellprofiler.org).

Real-time RT-PCR and RT-PCR. Total RNA was isolated from cells using TRIzol (Invitrogen), and the purity and concentration was measured spectrophotometrically. Single-stranded cDNA was synthetized using a First Strand cDNA Synthesis kit (Fermentas, Amherst NY, USA) with Oligo(dT)18 and $\mathrm{M}-\mathrm{MuLV}$ reverse transcriptase. The primers are shown in Table I. The primers specific for CXCR1 were purchased from the GeneCopoeia, Inc. (Guangzhou, China; cat. no: HQP009679). All real-time PCR reactions were performed using SYBR-Green Master Mix kit (Thermo Fisher Scientific, Rockville, MD, USA) using an ABI real-time PCR system. GADPH was used as the internal reference. Reactions were performed using the following conditions: denaturation at $95^{\circ} \mathrm{C}$ for $10 \mathrm{~min}, 40$ cycles at $95^{\circ} \mathrm{C}$ for $10 \mathrm{sec}$ and $60^{\circ} \mathrm{C}$ for $20 \mathrm{sec}$. The $2^{-\Delta \Delta \mathrm{Ct}}$ method was used to calculate the relative mRNA expression of target genes.

For RT-PCR, the cDNA template was amplified with Taq DNA polymerase (Tiangen Biotech Co., Ltd., Beijing, China). The reaction conditions used were denaturation at $94^{\circ} \mathrm{C}$ for $3 \mathrm{~min} ; 35$ cycles of denaturation at $94^{\circ} \mathrm{C}$ for $30 \mathrm{sec}$, annealing at $55-60^{\circ} \mathrm{C}$ for $30 \mathrm{sec}$, extension at $72^{\circ} \mathrm{C}$ for $30 \mathrm{sec}$; followed by an extension step at $72^{\circ} \mathrm{C}$ for $3 \mathrm{~min}$. PCR products were electrophoresed on a $1.5 \%$ of agarose gel. $\beta$-actin was used as the internal control.

Western blot analysis. Stable transfected cells were lysed

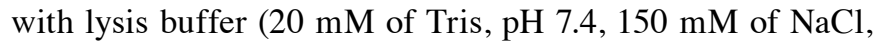
$2 \mathrm{mM}$ of EDTA and $1 \%$ Triton X-100) containing the protease inhibitor, phenylmethylsulfonyl fluoride (PMSF). Cells were centrifuged at $12,000 \mathrm{rpm}$ for $12 \mathrm{~min}$ at $4^{\circ} \mathrm{C}$, and the supernatant collected. Equal amounts of protein $(50 \mu \mathrm{g})$, quantified by BCA protein assay kit (Pierce Biotechnology, 
Rockford, IL, USA), were separated by sodium dodecyl sulfate-polyacrylamide electrophoresis (SDS-PAGE, $8-12 \%$ ). After electrophoresis, the separated proteins were electrophoretically transferred to polyvinylidene fluoride (PVDF) membranes (Millipore). Membranes were incubated in blocking solution containing 5\% non-fat milk for $1.5 \mathrm{~h}$ followed by incubation with the following primary antibodies against p-ERK-Thr202/Tyr204, p-AKT-Ser473 and AKT, (Anbo Biotechnology, Co., Ltd., San Francisco, CA, USA), and $\beta$-actin, CXCR1, Bcl-2, Bax, cyclin D1, EGFR, Ki-67, VEGF, MMP-9, MMP-2, E-cadherin, and GAPDH (Santa Cruz Biotechnology, Santa Cruz, CA, USA). Antibodies were used at a 1:500 dilution in TBST buffer overnight at $4^{\circ} \mathrm{C}$. After three washes, the blots were subsequently incubated with the appropriate horseradish peroxidase-conjugated secondary antibody (1:2,000 diluted in TBST buffer; Beijing Zhongshan Golden Bridge Biotechnology, Co., Ltd., Beijing, China) for $1 \mathrm{~h}$ at room temperature. GADPH used as a loading control. Proteins were detected using the enhanced chemiluminescence (ECL substrate; Pierce Biotechnology).

Gastric carcinoma xenograft mouse model. Thirty-six female BALB/c nude mice (4-6 weeks old and 18-22 g) were purchased from the Institute of Zoology, Chinese Academy of Sciences (Beijing, China) and housed at the Animal Care Center of the Third Hospital of Xiang-Ya, Central South University (Changsha, China). All experimental procedures were approved by the Animal Care and Ethics Committee of the Third Hospital of Xiang-Ya (no. 2012-10).

Mice were randomly divided into 6 groups: CXCR1shRNA-MKN45 group, scramble-shRNA-MKN45 group, MKN45 group, CXCR1-BGC823 group, vacant-BGC823 group and BGC823 group using a random number table. Cell suspension containing $2 \times 10^{7}$ cells in $0.2 \mathrm{ml}$ was injected into the right back region of each nude mouse. Tumor volume was measured using digital calipers once every two days: $\mathrm{V}=(\mathrm{a}$ $\mathrm{x}^{2}$ ) x 0.5 (a for length diameter, $\mathrm{b}$ for short diameter). The health and activity of the nude mice was monitored. Three weeks after the cell transplantation, the mice were euthanized under anesthesia and the transplantation tumor was cut and weighed. The tumor was fixed in $10 \%$ formaldehyde, embedded in paraffin, stained with $H \& E$ and observed under an inverted microscope.

Statistical analysis. The SPSS 13.0 software system (SPSS, Inc., Chicago, IL, USA) was used for statistical analysis. Data are expressed as mean \pm standard deviation (SD) from at least 3 independent experiments. Data were analyzed using one-way analysis of variance (ANOVA) with Turkey's test for post hoc analysis. $\mathrm{P}<0.05$ was considered to indicate a statistically significant difference.

\section{Results}

Establishment of gastric cancer cell lines with stable knockdown or overexpression of the CXCR1 gene. CXCR1 mRNA and protein expression levels revealed relatively higher expression in MKN45 cells and lower expression in BGC823 cells (Fig. 1A and B). In the subsequent experiments, the MKN45 cells were stably transfected with the
CXCR1 shRNA, and BGC823 cells were used to overexpress the CXCR1 gene.

MKN45 cells were transfected with the three plasmid vectors pYr-1.1-CXCR1-shRNA1 (CXCR1-shRNA1), CXCR1shRNA2 and CXCR1-shRNA3 to test the efficiency of CXCR1 knockdown by RT-PCR and western blot analysis. Based on the results plasmid vector pYr-1.1-CXCR1 shRNA-3 (CXCR1shRNA3) was chosen for the subsequent experiments.

To verify that the knockdown of CXCR1 expression by RNAi was efficient and that no off-target effects existed, we performed CXCR1 RNAi rescue experiments. CXCR1 protein levels in cells transfected with the pIRES2-ZsGreen1-CXCR1Mut were not different from those transfected with both the mutant and pYr-1.1-CXCR1-shRNA3 (CXCR1-shRNA), but CXCR1 protein levels in cells transfected with CXCR1-shRNA alone were obviously reduced compared to the non-transfected MKN45 cells (Fig. 1C). These results suggested that the CXCR1-shRNA-mediated RNA interference of the CXCR1 gene in MKN45 cells did not have off-target effects.

CXCR1-shRNA and the control plasmid vector, pYr1.1-CXCR1-scramble shRNA (scramble-shRNA), were stably transfected into MKN45 cells, respectively. One month after the screening with G418, CXCR1 mRNA and protein levels were measured in CXCR1-shRNA and scramble-shRNA cell clones by real-time RT-PCR and western blot analysis (Fig. 1D and E). CXCR1 expression was lower in CXCR1-shRNA cells than non-transfected MKN45 cells and scramble-shRNA cells (all $\mathrm{P}<0.05)$. CXCR1mRNA and protein levels were also measured in BGC823 cells after stable transfection with the expression plasmid, pIRES2-ZsGreen1-CXCR1 (CXCR1-BGC823) and pIRES2-ZsGreen1 (vacant-BGC823) (Fig. 1F and G). CXCR1 mRNA and protein levels in CXCR1-BGC823 cell clones were higher than those in the vacant-BGC823 or non-transfected BGC823 cells (all $\mathrm{P}<0.05$ ).

Effects of CXCR1 stable knockdown or overexpression on the proliferation and growth of gastric carcinoma cells. Cell proliferation indicated as absorbance over a 72-h period was measured using the MTT assay in MKN45 cells stably transfected with CXCR1-shRNA, scrambled-shRNA or non-transfected cells. Cell proliferation was lower in the CXCR1-shRNA-MKN45 group than the MKN45 and scramble-shRNA-MKN45 groups over a 72-h period (all $\mathrm{P}<0.05$ ) (Fig. 2A). However, stable overexpression of CXCR1 in the CXCR1-BGC823 cells promoted cell proliferation and growth significantly above the BGC823 and vacant-BGC823 groups over a 72-h period (all $\mathrm{P}<0.05)$ (Fig. $2 \mathrm{~B}$ ). There was no significant difference in the proliferation or growth between the MKN45 and vcramble-shRNA-MKN45 cells, or between the BGC823 and vacant-BGC823 cells (all P>0.05) (Fig. 2A and $\mathrm{B})$.

In order to further establish the role of CXCR1 stable knockdown or overexpression on the proliferation and growth of gastric carcinoma cells, the proliferative capacity of single cells was measured using a plate colony formation assay. The cloning efficiency in the CXCR1-shRNA-MKN45 group was significantly lower than the MKN45 and scramble-shRNAMKN45 groups (both $\mathrm{P}<0.05$ ). No significant difference in cloning efficiency was detected between scramble-shRNAMKN45 and non-transfected MKN45 cells (Fig. 2C). The 

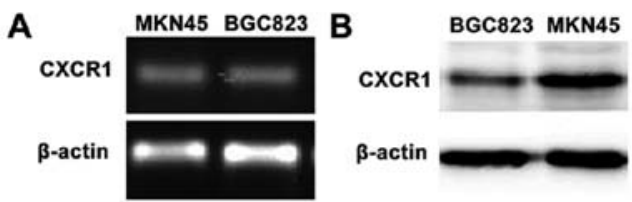

D

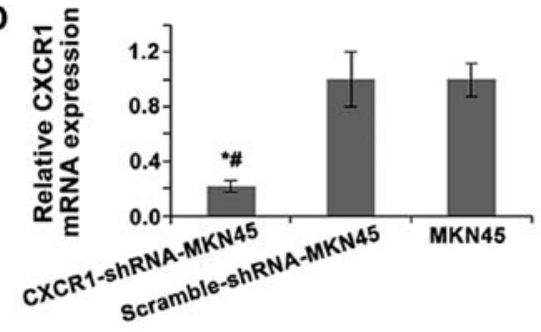

$\mathbf{F}$

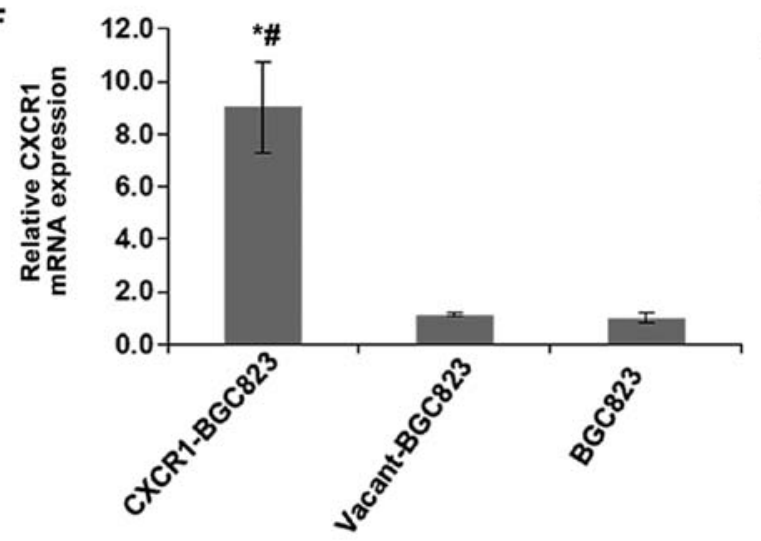

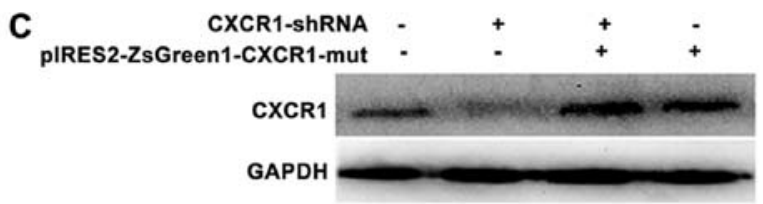
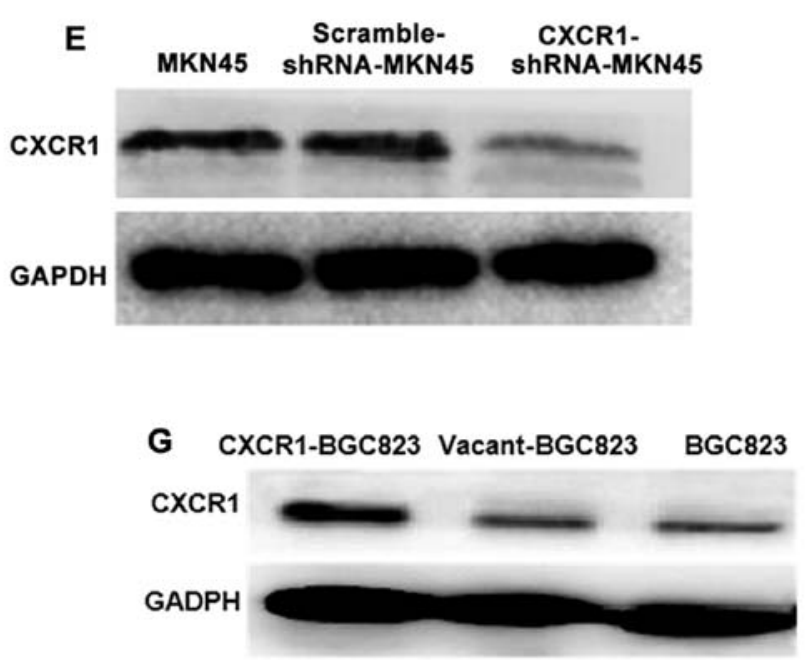

Figure 1. Effects of CXCR1 stable knockdown and overexpression on CXCR1 mRNA and protein expression in gastric carcinoma cell lines. (A) CXCR1 mRNA expression in MKN45 and BGC823 cells was determined by RT-PCR; (B) CXCR1 protein expression in MKN45 and BGC823 cells was determined by western blot analysis. $\beta$-actin was used as an internal control. (C) CXCR1 protein expression in the MKN45 cells transfected with plasmid vectors pYr-1.1CXCR1-shRNA-3 (CXCR1-shRNA) and pIRES2-ZsGreen1-CXCR1-Mut was determined by western blot analysis. GAPDH was used as an internal control. MKN45 cells were stably transfected with CXCR1-shRNA and pYr-1.1-scramble-shRNA (scramble-shRNA) using G418 resistance screening for 1 month. (D) CXCR1 mRNA expression was determined by real-time RT-PCR; (E) CXCR1 protein expression was determined by western blot analysis. GAPDH was used as an internal control. BGC823 cells were stably transfected with plasmid pIRES2-ZsGreen1-CXCR1 (CXCR1-BGC823) and pIRES2-ZsGreen1 (vacantBGC823) using G418 resistance screening for 1 month. (F) CXCR1 mRNA expression was determined by real-time RT-PCR; (G) CXCR1 protein expression was determined by western blot analysis. GAPDH was used as an internal control. Data are shown as mean \pm standard deviation (SD). "P<0.05 vs. MKN45 or BGC823; ${ }^{" P}<0.05$ vs. scramble-shRNA-MKN45 or vacant-BGC823.

cloning efficiency of CXCR1-BGC823 cells was significantly higher than the BGC823 and vacant-BGC823 cells (both $\mathrm{P}<0.05)$ and no significant differences were found in the cloning efficiency between vacant-BGC823 and non-transfected BGC823 cells (Fig. 2D).

\section{Effects of CXCR1 stable knockdown or overexpression on cell} cycle distribution and apoptosis of gastric carcinoma cells. To investigate the effects of CXCR 1 stable knockdown or overexpression on cell cycle distribution and apoptosis, cells were analyzed by flow cytometry using PI. The proportion of MKN45 cells at the G2/M phase significantly decreased in the CXCR1-shRNA-MKN45 group (both $\mathrm{P}<0.05$ ) and the percentage of apoptotic cells increased significantly (both $\mathrm{P}<0.05$ ) relative to the control groups, MKN45 and scramble-shRNA-MKN45. There was no significant difference in the proportion of cells at the G2/M phase or percentage of apoptotic cells between the scramble-shRNAMKN45 and MKN45 groups (Fig. 3A). The proportion of BGC823 cells at the G2/M phase significantly increased in the CXCR1-BGC823 group (both $\mathrm{P}<0.05$ ) and the percentage of apoptotic cells significantly decreased (both $\mathrm{P}<0.05$ ) relative to the control groups, vacant-BGC823 and BGC823. There was no significant difference in the proportion of cells at the G2/M phase or percentage of apoptotic cells between the vacant-BGC823 and BGC823 groups (Fig. 3B).

\section{Effects of CXCR1 stable knockdown or overexpression} on the migration and invasion of gastric carcinoma cells. To investigate the effects of CXCR1 stable knockdown or overexpression on the migration and invasion of gastric carcinoma cells, a Transwell migration/invasion assay was used. CXCR1-shRNA-MKN45 cells revealed a decrease in the number of cells that migrated (both $\mathrm{P}<0.05$ ) or invaded (both $\mathrm{P}<0.05$ ) the Transwell membrane relative to non-transfected MKN45 or scramble-shRNA-MKN45 cells (Fig. 4A). There was no significant difference in the number of cells that migrated and invaded through the Transwell membrane between the scramble-shRNA-MKN45 and the MKN45 groups (Fig. 4A). BGC823 cells overexpressed CXCR1 

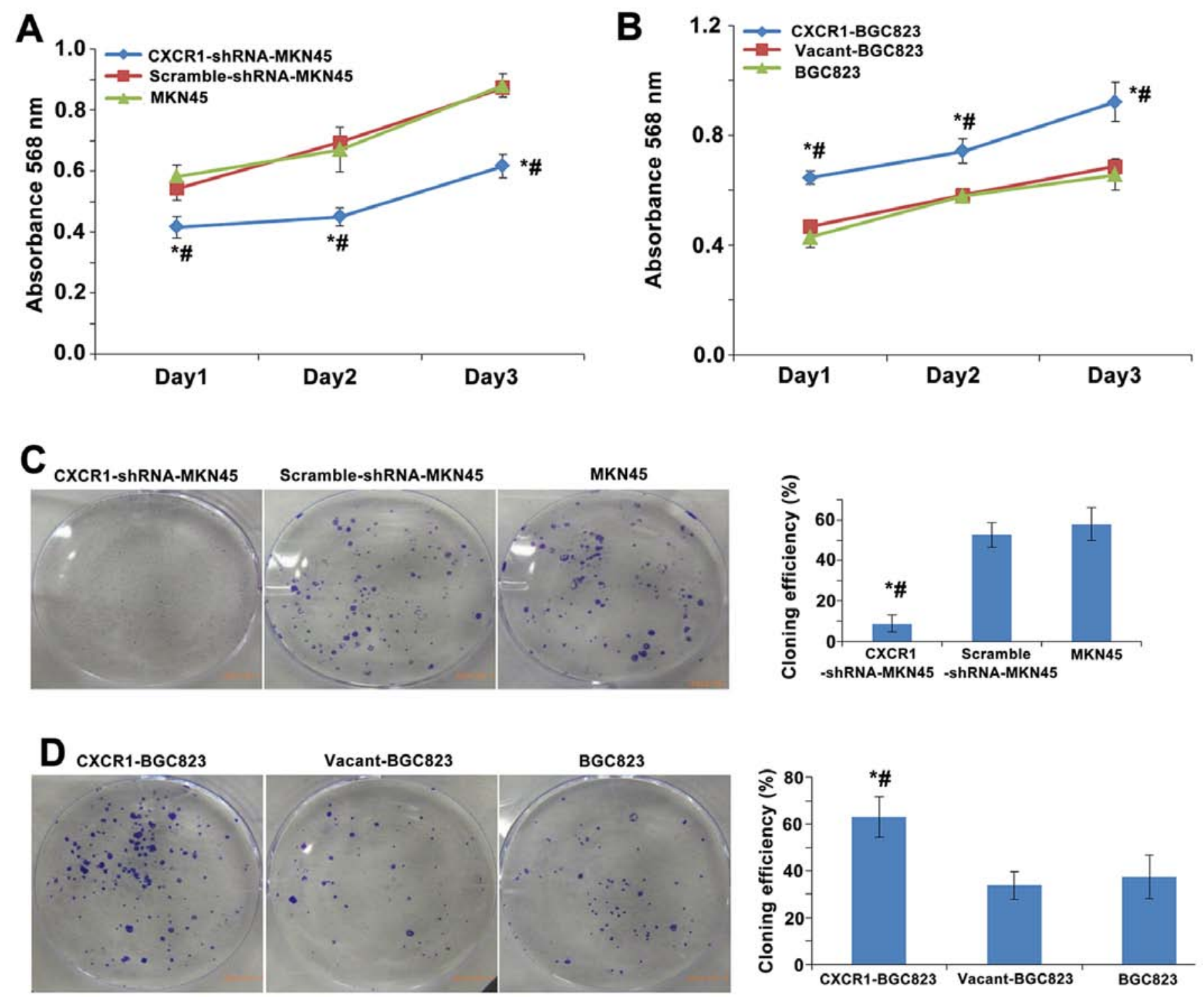

Figure 2. Effects of CXCR1 stable knockdown in MKN45 cells and CXCR1 stable overexpression in BGC23 cells on cell proliferation and growth. MKN45 cells were stably transfected with CXCR1-shRNA and scramble-shRNA using G418 resistance screening for 1 month. (A) Cell proliferation was analyzed by MTT assay. (C) Cell growth was determined by colony forming assay. BGC23 cells were stably transfected with BGC823/pIRES2-ZsGreen1-CXCR1 (CXCR1-BGC823) and BGC823/pIRES2-ZsGreen1-NC (vacant-BGC823) using G418 resistance screening for 1 month. (B) Cell proliferation was analyzed by MTT assay. (D) Cell growth was determined by colony forming assay. Data are shown as mean \pm SD. ${ }^{*} \mathrm{P}<0.05$ vs. MKN 45 or BGC23; ${ }^{*} \mathrm{P}<0.05$ vs. scrambleshRNA-MKN45 or vacant-BGC823.

(CXCR1-BGC823 group) showed an increase in the number of cells that migrated (both $\mathrm{P}<0.05$ ) or invaded (both $\mathrm{P}<0.05$ ) the Transwell membrane relative to non-transfected BGC823 cells or the vacant-BGC823 cells (Fig. 4B). There was no significant difference in the number of cells that migrated or invaded the Transwell membrane between the BGC 823 and vacant-BGC823 groups (Fig. 4B).

In order to further investigate the effect of CXCR1 stable knockdown or overexpression on the migration and invasion of gastric carcinoma cells, wound-healing assay was conducted. The wound closure rate of CXCR1-shRNA-MKN45 cells was significantly less than non-transfected MKN45 cells and scramble-shRNA-MKN45 cells (both $\mathrm{P}<0.05)$. No obvious differences in the wound closure rates between the scramble-shRNA-MKN45 cells and non-transfected MKN45 cells were detected (Fig. 4C). The rate of wound closure of
CXCR1-BGC823 cells was significantly higher than nontransfected BGC823 cells and the vacant-BGC823 cells (both $\mathrm{P}<0.05)$. Wound closure rates of the vacant-BGC823 and BGC823 groups were not different (Fig. 4D).

Effect of CXCR1 stable knockdown or overexpression on the in vivo tumor growth of gastric carcinoma cells. To investigate the effect of CXCR1 stable knockdown or overexpression on the ability of gastric carcinoma cells to form tumors, gastric carcinoma cells were transplanted into nude mice. The weight and volume of the tumors formed in nude mice injected with CXCR1-shRNA-MKN45 cells was significantly smaller than mice transplanted with control, MKN45 cells or scramble-shRNA-MKN45 cells (both $\mathrm{P}<0.05$ ). The weight and volume of the xenografts in nude mice were not different between the MKN45 and the scramble-shRNA- 

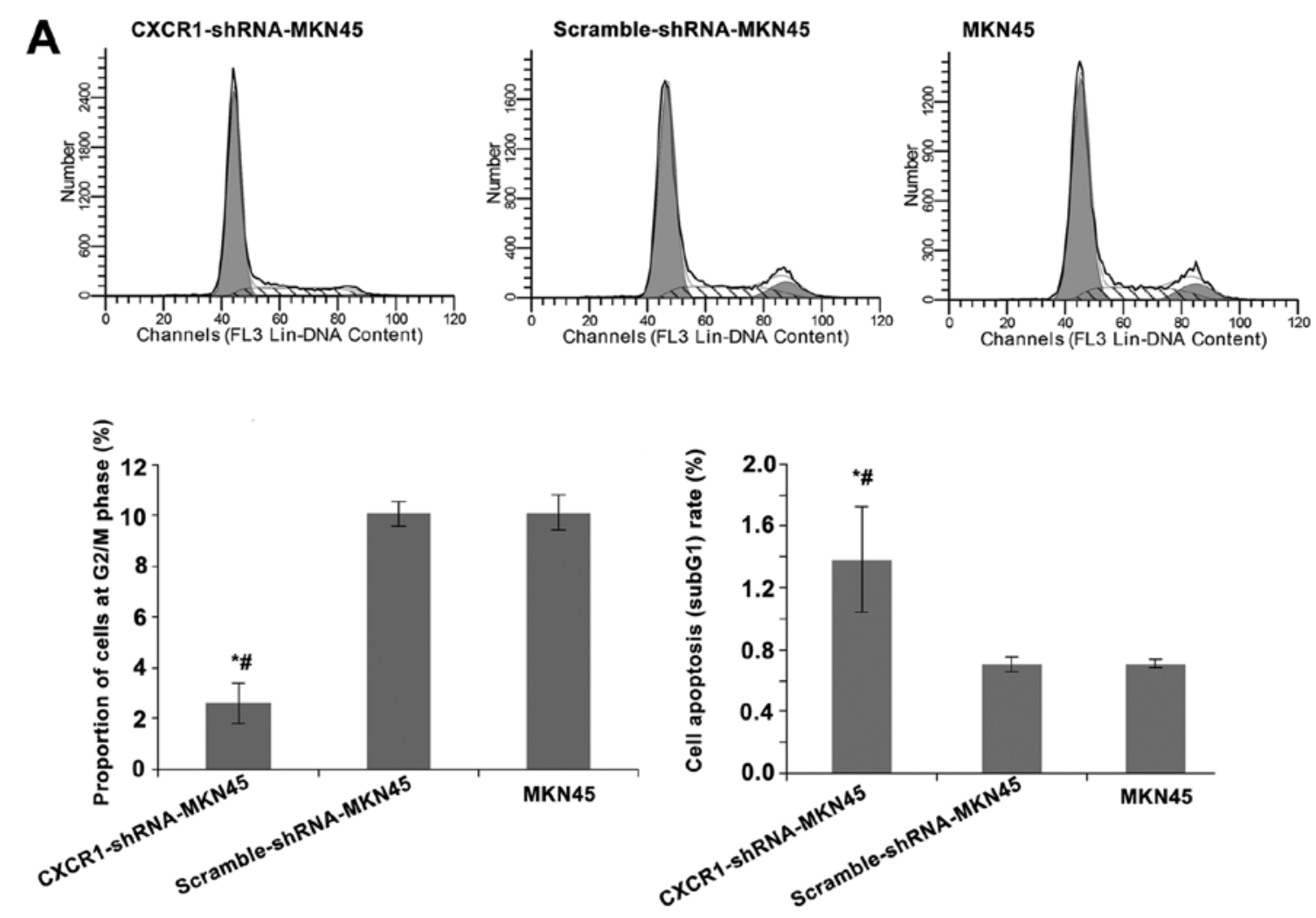

B

Vacant-BGC823

BGC823
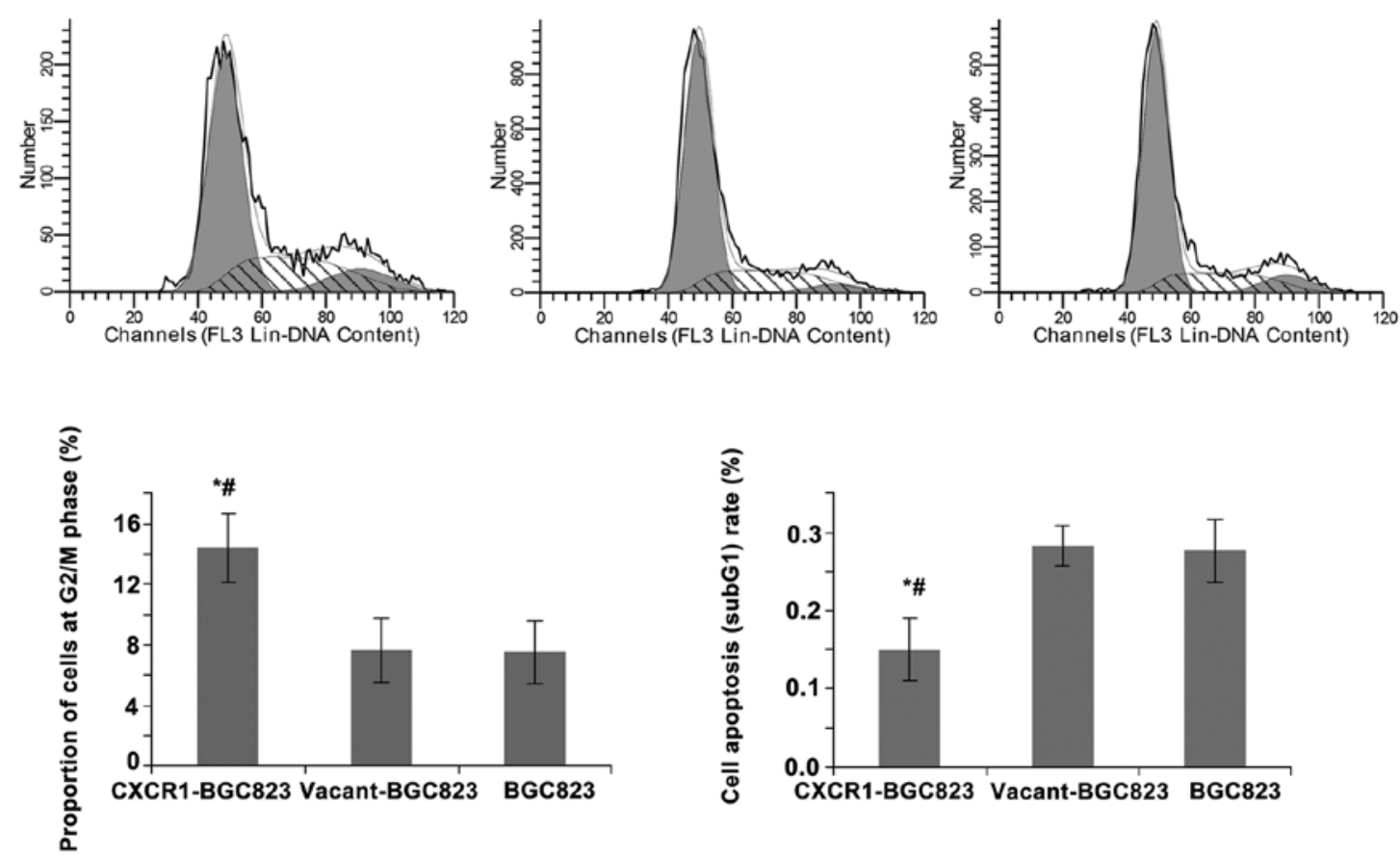

Figure 3. Effects of CXCR1 stable knockdown in MKN45 cells and CXCR1 stable overexpression in BGC23 cells on cell cycle distribution and apoptosis. Cell cycle at G2/M phase and apoptosis (sub-G1) were determined by flow cytometric analysis using propidium iodide staining in MKN45 cells (A) and BGC23 cells (B). Data are shown as mean $\pm \mathrm{SD}$. ${ }^{*} \mathrm{P}<0.05$ vs. MKN45 or BGC23; $\mathrm{P}<0.05$ vs. scramble-shRNA-MKN45 or vacant-BGC823.

MKN45 groups (Fig. 5A). H\&E staining confirmed that the xenografts were composed of cancer cells rather than abscesses (Fig. 5B). Furthermore, in nude mice transplanted with CXCR1-BGC823 cells, the weight and volume of the resulting tumors was significantly larger (both $\mathrm{P}<0.05$ ) than mice transplanted with BGC 823 cells or vacant-BGC 823 cells. There was no significant difference in the weight and volume of xenografts in nude mice between the BGC 823 and vacant- 

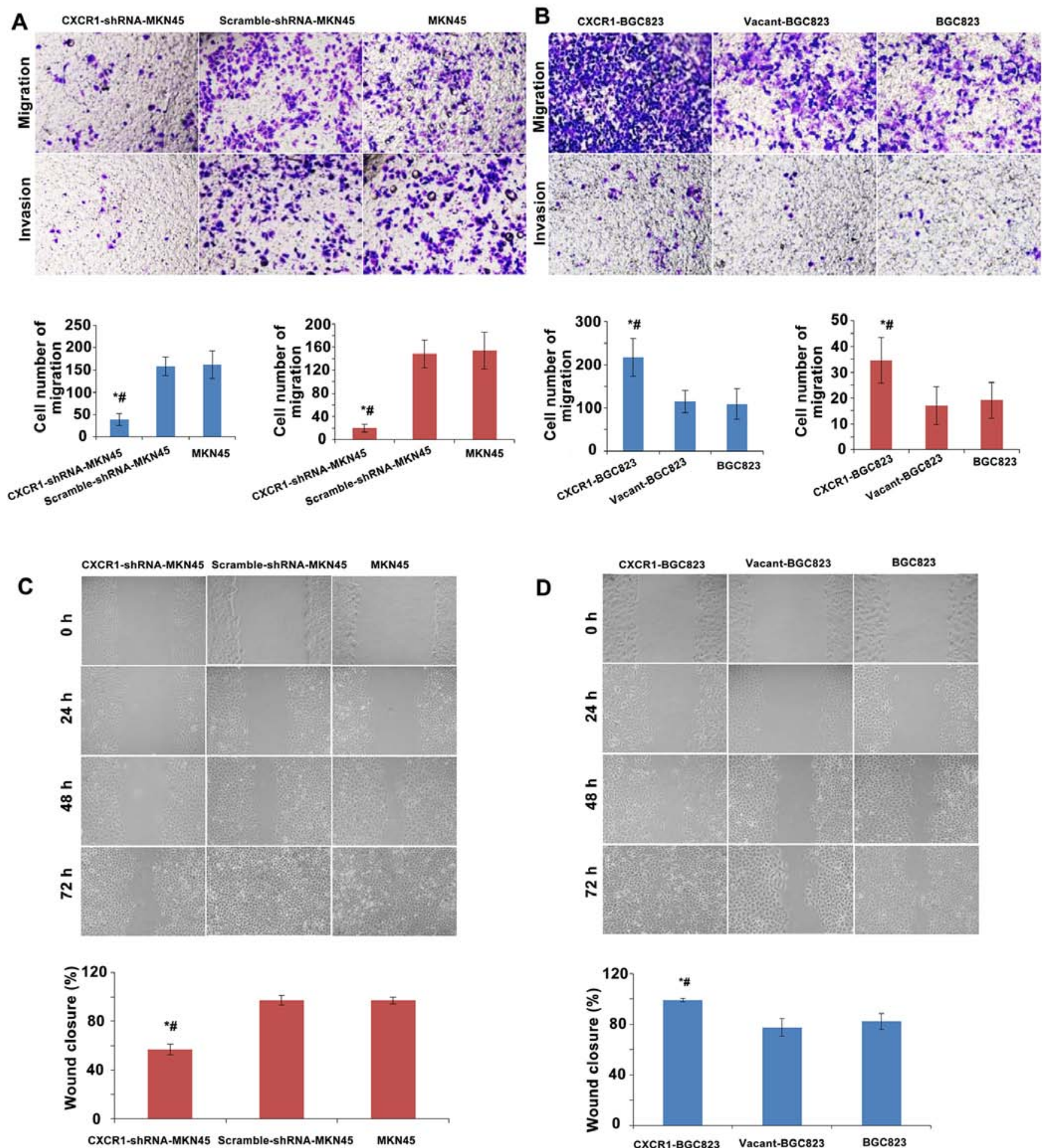

Figure 4. Effects of CXCR1 stable knockdown in MKN45 cells and CXCR1 stable overexpression in BGC23 cells on cell migration and invasion. (A and B) cells were plated on non-coated or Matrigel-coated membranes for migration (up) and invasion (down) assays and incubated for $12 \mathrm{~h}$ (magnification, x200). Migrated and invading cells were counted in 10 random fields (magnification, x200) and expressed as the average number of cells per field of view. (C and D) Wound healing assay: Images obtained at $0,24,48$ and $72 \mathrm{~h}$ after scratch formation. Wound closure $(\%)=$ [Cell-free area $(0 \mathrm{~h})-\mathrm{Cell}-\mathrm{free}$ area $(72 \mathrm{~h})] / \mathrm{Cell}-\mathrm{free}$ area $\left(0\right.$ h). Data are shown as mean \pm SD. ${ }^{*} \mathrm{P}<0.05$ vs. MKN45 or BGC23; ${ }^{*} \mathrm{P}<0.05$ vs. scramble-shRNA-MKN45 or vacant-BGC823.

BGC823 groups (Fig. 5C). H\&E staining confirmed that the xenografts resulting from CXCR1 overexpressing cells were composed of cancer cells rather than abscesses (Fig. 5D).

Effects of CXCRI stable knockdown on the levels of AKT and ERK1/2 phosphorylation and markers of apoptosis, prolifera- tion and growth, angiogenesis, invasion and metastasis related signaling molecules in MKN45 cells. In order to determine whether the AKT and ERK1/2 signal pathways were activated by CXCR1 receptor/ligand interaction, phosphorylation of AKT and ERK1/2 was measured in the MKN45 cells stably transfected with a CXCR1 specific shRNA. Phosphorylated 

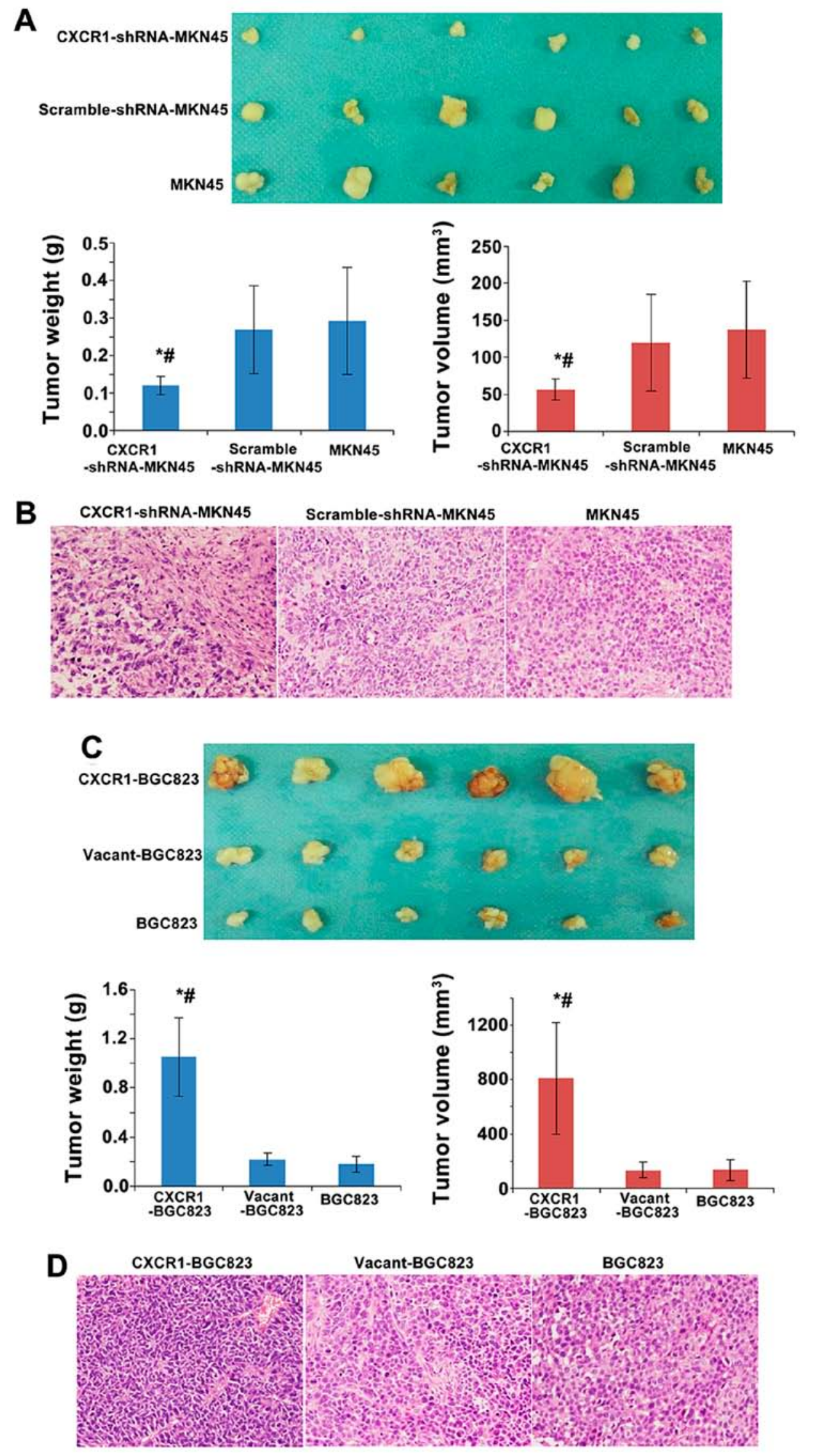

Figure 5. Effects of CXCR1 stable knockdown in MKN45 cells and CXCR1 stable overexpression in BGC23 cells on tumor volume, tumor weight and pathology in the gastric carcinoma xenograft mouse model. Thirty-six nude mice were divided into 6 groups: CXCR1-shRNA-MKN45; scramble-shRNAMKN45; MKN45 cells; CXCR1-BGC823; vacant-BGC823; and BGC823 cells. Cell suspension $(0.2 \mathrm{ml})$ containing $2 \times 10^{7}$ viable cells were inoculated in the right rear back of each nude mouse. Three weeks after inoculation, mice were euthanized, and tumor tissues from each group were collected. (A and C) Tumor weight and volume. (B and D) Pathology was determined by hematoxylin and eosin (H\&E) staining (magnification, $\mathrm{x} 200$ ). Data are shown as mean $\pm \mathrm{SD}$ ( $\mathrm{n}=6$ / group). ${ }^{*} \mathrm{P}<0.05$ vs. MKN45 or BGC23; $\mathrm{P}<0.05$ vs. scramble-shRNA-MKN45 or vacant-BGC823. 

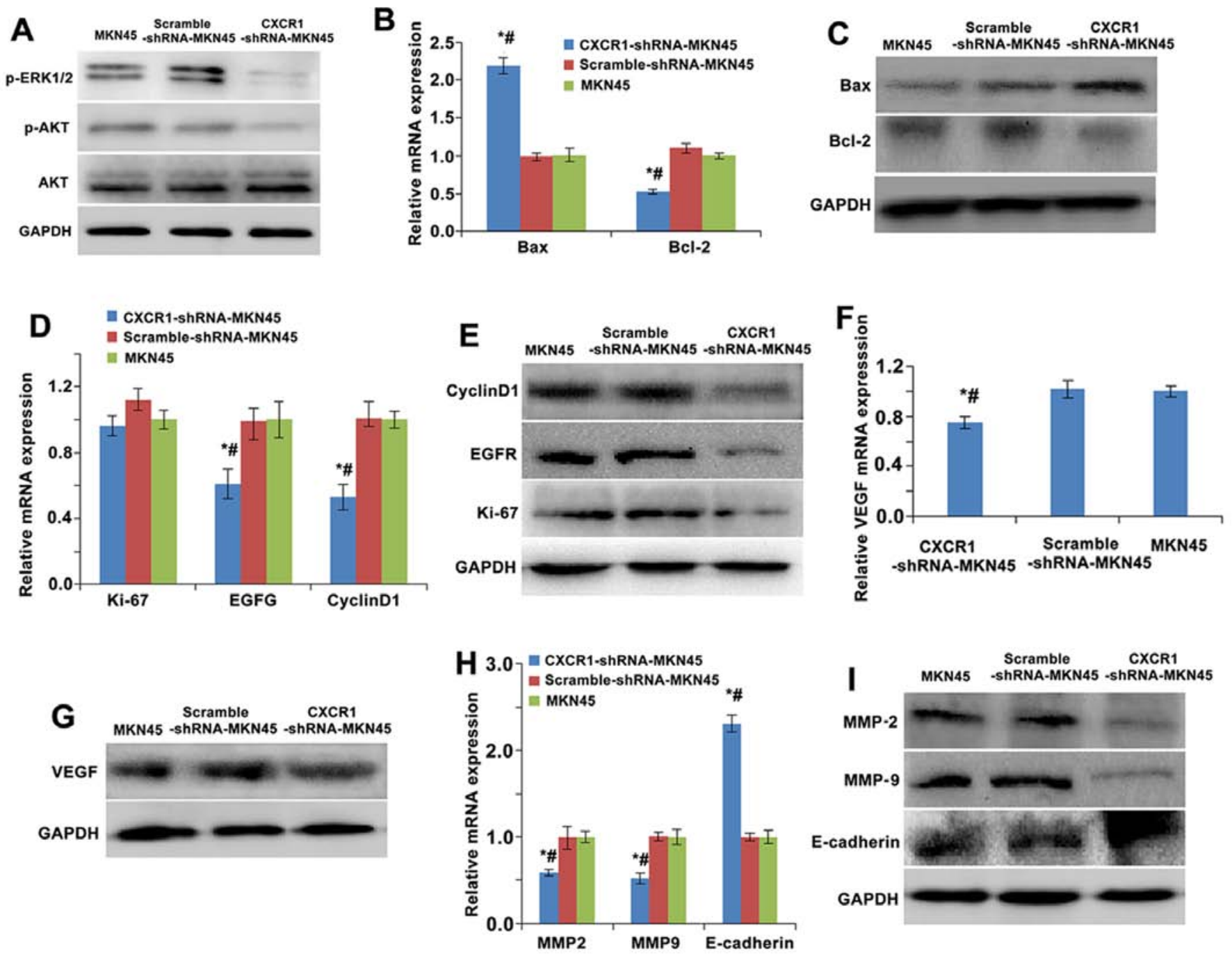

Figure 6. Effects of CXCR1 stable knockdown in MKN45 cells on cell proliferation, cell cycle, cell apoptosis, cell migration and invasion-related signaling molecule expression. (A) Phosphorylation of AKT and ERK1/2 was determined by western blot analysis. mRNA expression of apoptosis (Bcl-2 and Bax) (B), proliferation and growth (cyclin D1, EGFR and Ki-67) (D), angiogenesis (VEGF) (F), invasion and metastasis (MMP-9, MMP-2 and E-cadherin) (H) was determined by real-time RT-PCR. Protein expression of apoptosis (Bcl-2 and Bax) (C), proliferation and growth (cyclin D1, EGFR and Ki-67) (E), angiogenesis (VEGF) (G), invasion and metastasis (MMP-9, MMP-2 and E-cadherin) (I) were determined by western blotting. GAPDH was used as a loading control. Data are shown as mean $\pm \mathrm{SD}$. ${ }^{*} \mathrm{P}<0.05$ vs. MKN45; ${ }^{\#} \mathrm{P}<0.05$ vs. scramble-shRNA-MKN45.

AKT (p-AKT) and p-ERK1/2 levels, detected by western blot analysis, were lower in the CXCR1-shRNA-MKN45 group than the MKN45 and scramble-shRNA-MKN45 groups, but total AKT levels were not different among the three groups. There was no difference in the phosphorylated and total AKT and ERK1/2 levels between scramble shRNA-MKN45 and MKN45 groups (Fig. 6A).

To investigate the mechanism by which CXCR 1 regulates apoptosis, we measured the expression of apoptotic genes (Bax and BCL-2) by real-time RT-PCR and western blot analysis. The expression of Bcl-2 in the CXCR1-shRNA-MKN45 group was lower than the levels in the MKN45 and scramble-shRNAMKN45 groups. In contrast the CXCR1 shRNA increased the expression of Bax. No difference in the expression of Bax and Bcl-2 were detected between the scramble-shRNA-MKN45 and MKN45 groups (Fig. 6B and C).

To elucidate the potential mechanism by which CXCR1 shRNA inhibits the proliferation of gastric carcinoma cells, the expression of proliferation, and growth- and cell cycle- related genes (cyclin D1, EGFR and Ki-67) were evaluated. Real-time RT-PCR revealed lower EGFR and cyclin D1 mRNA levels in CXCR1-shRNA-MKN45 cells compared to MKN45 and scramble-shRNA-MKN45 cell groups (all $\mathrm{P}<0.05$ ). The level of $\mathrm{Ki}-67$ was not altered by CXCR1 RNA interference. Furthermore, cyclin D1, EGFR and Ki-67 mRNA levels were not different between scramble-shRNAMKN45 and MKN45 cells (Fig. 6D and E). Western blots showed that the expression of cyclin D1, EGFR and Ki-67 in CXCR1-shRNA-MKN45 cells were significantly lower than in the MKN45 and scramble-shRNA-MKN45 groups. Cyclin D1, EGFR and Ki-67 protein levels were not different between the scramble-shRNA-MKN45 and MKN45 groups (Fig. 6D and E).

As an indicator of tumor angiogenesis, VEGF mRNA and protein levels were measured by real-time RT-PCR and western blot analysis, respectively, and were found lower in CXCR1-shRNA-MKN45 cells than in the MKN45 and scramble-shRNA-MKN45 groups. No differences were found 
in the expression of VEGF between the scramble-shRNAMKN45 and MKN45 groups (Fig. 6F and G).

To further understand the possible mechanism by which inhibition of CXCR1 expression could inhibit the invasion and metastasis of gastric carcinoma cells, the expression of several markers of cell invasion and metastasis (MMP-9, MMP-2 and E-cadherin) were measured. In CXCR1-shRNA-MKN45 group the expression of MMP-2 and MMP-9 at both the mRNA and protein levels were lower and E-cadherin higher than the MKN45 and scramble-shRNA-MKN45 groups. No differences in the expression of MMP-9, MMP-2 or E-cadherin were observed between the scramble-shRNA-MKN45 and MKN45 groups (Fig. 6H and I).

\section{Discussion}

The association of high CXCR1 levels with several types of aggressive and invasive cancers warrants a more complete understanding of the function of this pro-inflammatory chemokine in permissive tumor cell environments (10). This is especially true in the gastrointestinal tract where chronic states of inflammation may promote the transformation of a cancer cell phenotype. In order to elucidate the functional role of CXCR1 in the development of gastric cancer, both loss of function and gain of function approaches were used to characterize gastric carcinoma cell proliferation, invasion and migration in vitro. This was accomplished by developing stable transfected cell lines containing a CXCR1-shRNA to inhibited CXCR1 expression, or CXCR1 coding sequence to overexpress the gene. These well characterized high and low CXCR1 expressing gastric carcinoma cells lines were then used as xenografts in nude mice to test their potential for tumor formation. The data collected from these experiments clearly indicate that CXCR1 expression promotes the proliferation and growth, and enhances the migration and invasion properties of gastric carcinoma cells.

To establish a cell line with CXCR1 loss-of-function using RNAi technology, several steps were incorporated to design and test shRNA that both were efficient and specific. The first step was to choose a cell system with high CXCR1 expression to characterize the shRNA. MKN45 cells with relatively higher CXCR1 expression were chosen for the RNA interference experiments. Next, three shRNA fragments were successfully sub-cloned into the plasmid pYr 1.1. All three shRNA tested in transient transfection assays suppressed CXCR1 expression, and pYr-1.1-CXCR1-shRNA-3 was chosen for stable transfections. Subsequent G418 screening, real-time RT-PCR and western blot testing were used to establish a stable CXCR1-shRNA-MKN45 cell line, which provided a tool for the subsequent research on the function of CXCR1.

To verify that the knockdown of CXCR1 expression by RNAi was efficient and that no off-target effects existed, we carried out CXCR1 RNAi rescue experiments, as first proposed by Jackson and colleagues (20). Cells transfected with a single gene-specific siRNA have been reported to interfere with the expression of a large number of non-specific genes in genome wide screens with altered expression levels of 1.5 - to 3 -fold (21). To verify there were no off-target effects in our experiment, we mutated 3 bases according to the target sites of the CXCR1 gene to prevent the interference sequence of pYr-1.1-CXCR1-shRNA-3. The pYr-1.1-CXCR1-shRNA-3 (CXCR1-shRNA) and pIRES2-ZsGreen1-CXCR1-Mut were transfected at the same time into MKN45 cells. Compared with the pIRES2-ZsGreen1-CXCR1-Mut alone group, the expression of CXCR1 in MKN45 cells transfected with both the pIRES2-ZsGreen1-CXCR1-Mut and CXCR1-shRNA did not interfere with CXCR1 expression and suggested that there were no off-target effects in our experiment.

The occurrence and development of gastric cancer is complex and involves aberrant regulation of proliferation, invasion and metastasis of cancer cells. To investigate the role of CXCR1 in the development of gastric cancer, we observed the effect of CXCR1 knockdown or overexpression on the proliferation, cell cycle distribution, and apoptosis of gastric carcinoma cells by MTT, plate colony formation and flow cytometry assays. The results showed CXCR1 knockdown inhibited cell proliferation and growth. This was accompanied by $\mathrm{G} 2 / \mathrm{M}$ phase arrest and cell apoptosis. Importantly, CXCR1 stable knockdown prevented the in vivo formation of tumors when cells were transplanted into mice. The opposite result was observed when CXCR1 overexpressing cells were used as xenografts, and much larger tumors were observed in the nude mice. Thus, CXCR1 participates in the development of gastric tumors by inhibiting apoptosis and promoting the proliferation and growth of gastric cancer cells. The results were consistent with the role of CXCR1 in other cancers (11-15).

Invasion and metastasis are also the important manifestations of gastric cancer and often the reason for poor patient prognosis. Many factors also regulate the invasion and metastasis of cancer cells. In order to explore the role of CXCR1 in gastric cancer cell invasion and metastasis, the ability of cells to transverse non-coated and Matrigel-coated membranes was tested in a Transwell system. This experiment was complimented with wound-healing assay to monitor cell migration rates. Results from these in vitro measurements, again using knockdown and overexpression cell lines, showed that CXCR1 knockdown inhibited the migration and invasion properties of gastric carcinoma cells while the overexpression of CXCR1 increased the migration and invasion potential of cancer cells. These results are in line with the findings from the recent study (22).

To further explore the mechanism by which CXCR1 regulates altered proliferation, growth, apoptosis, invasion and migration in loss-of-function and gain-of-function culture models, the expression of several key genes involved in these cellular functions was measured. Previous studies have found that the abnormal phosphorylation of AKT and ERK1/2 was associated with the proliferation, growth, angiogenesis, invasion and metastasis of gastric cancer $(23,24)$, and was regarded as the bridge between CXCR $1 / 2$ and downstream molecules $(10,25,26)$. Our results confirm this finding and show that CXCR1 knockdown suppressed the phosphorylation of AKT and ERK1/2. This finding suggests CXCR1 receptor/ligand interactions might regulate the AKT and ERK1/2 signaling pathway. The ratio of Bcl-2 to Bax of Bcl-2 family are key indicators of tumor apoptosis with high expression of $\mathrm{Bcl}-2$ and low expression of Bax considered to inhibit apoptosis of cancer cells (27). In the present experiments CXCR1 knockdown induced apoptosis of gastric cancer cells and was accompanied by the upregulation of Bax and downregulation 
of Bcl-2. In addition to enhancing apoptosis, inhibition of CXCR1 decreased proliferation and this was accompanied by the downregulation of several proliferation genes (cyclin D1, and EGFR) associated with gastrointestinal tumors as well as many other types of cancers (28-31).

The next set of molecules characterized in these CXCR1 in vitro models was the balance between MMP-9, MMP-2 and E-cadherin. MMPs are well known to play an indispensable role in the invasion and metastasis of cancers through their ability to degrade extracellular matrix allowing the invasion and metastasis of cancer cells (32-35). E-cadherin is a cell surface adhesion molecule involved in cell-cell and cellmatrix interactions, and studies support a role for the loss of E-cadherin in the invasion of cancer cells $(36,37)$. In the present experimental system knockdown of CXCR1 decreased MMP-2 and MMP-9 and increased E-cadherin expression, and is consistent with a less invasive cancer cell phenotype.

Another characteristic of an aggressive, invasive tumor is the ability to form new blood vessels that supply the tumor with nutrition for the growth and provided a conduit for metastasis (38). The levels of VEGF, an angiogenic factor, are closely correlated with microvascular density in many types of tumors (39). Our experiments showed that CXCR1 knockdown resulted in decreasing VEGF expression, and thus further suggests that high CXCR1 levels could be associated with a highly aggressive, vascularized tumor.

CXCR1 silence inhibited proliferation and growth, induced cell cycle arrest and apoptosis and prevented migration and invasion ability of gastric cancer cells. However, overexpression of CXCR1 could reverse the above malignant behavior of gastric cancer cells, possibly relating to the phosphorylation level of AKT and ERK1/2 and the expression of BCL-2, cyclin D1, EGFR and VEGF, MMP-2, MMP-9, Bax and E-cadherin. Further study is necessary to fully clarify the interaction and regulation of these genes in gastric cancer cells. This study provides preclinical data to support CXCR1 as a novel therapeutic target for gastric cancer.

\section{Acknowledgements}

The present study was partially supported by the China Postdoctoral Science Foundation (no. 2014M562137), the Hunan Provincial Innovation Foundation for Postgraduate (no. CX2011B046), the Science and Technology Program Foundation of Changsha City (nos. K1005005-31 and K1106041-31).

\section{References}

1. Siegel R, Naishadham D and Jemal A: Cancer statistics, 2013. CA Cancer J Clin 63: 11-30, 2013.

2. Herszényi L and Tulassay Z: Epidemiology of gastrointestinal and liver tumors. Eur Rev Med Pharmacol Sci 14: 249-258, 2010

3. Brenner H, Rothenbacher D and Arndt V: Epidemiology of stomach cancer. Methods Mol Biol 472: 467-477, 2009.

4. Kusano T, Shiraishi N, Shiroshita H, Etoh T, Inomata M and Kitano S: Poor prognosis of advanced gastric cancer with metastatic suprapancreatic lymph nodes. Ann Surg Oncol 20: 2290-2295, 2013.

5. Murphy PM, Baggiolini M, Charo IF, Hébert CA, Horuk R, Matsushima K, Miller LH, Oppenheim JJ and Power CA: International Union of Pharmacology. XXII. Nomenclature for chemokine receptors. Pharmacol Rev 52: 145-176, 2000.
6. Zlotnik A and Yoshie O: Chemokines: A new classification system and their role in immunity. Immunity 12: 121-127, 2000.

7. Balkwill F: Cancer and the chemokine network. Nat Rev Cancer 4: 540-550, 2004.

8. Wells TN, Lusti-Narasimhan M, Chung CW, Cooke R, Power CA Peitsch MC and Proudfoot AE: The molecular basis of selectivity between CC and CXC chemokines: The possibility of chemokine antagonists as anti-inflammatory agents. Ann NY Acad Sci 796 (1 Cytokines): 245-256, 1996.

9. Vandercappellen J, Van Damme J and Struyf S: The role of CXC chemokines and their receptors in cancer. Cancer Lett 267: 226-244, 2008

10. Waugh DJ and Wilson C: The interleukin-8 pathway in cancer. Clin Cancer Res 14: 6735-6741, 2008.

11. Singh S, Nannuru KC, Sadanandam A, Varney ML and Singh RK: CXCR1 and CXCR2 enhances human melanoma tumourigenesis, growth and invasion. Br J Cancer 100: 1638-1646, 2009.

12. Ginestier C, Liu S, Diebel ME, Korkaya H, Luo M, Brown M, Wicinski J, Cabaud O, Charafe-Jauffret E, Birnbaum D, et al: CXCR1 blockade selectively targets human breast cancer stem cells in vitro and in xenografts. J Clin Invest 120: 485-497, 2010.

13. Chen Y, Shi M, Yu GZ, Qin XR, Jin G, Chen P and Zhu MH: Interleukin-8, a promising predictor for prognosis of pancreatic cancer. World J Gastroenterol 18: 1123-1129, 2012.

14. Li A, Varney ML and Singh RK: Expression of interleukin 8 and its receptors in human colon carcinoma cells with different metastatic potentials. Clin Cancer Res 7: 3298-3304, 2001.

15. Yang G, Rosen DG, Liu G, Yang F, Guo X, Xiao X, Xue F, Mercado-Uribe I, Huang J, Lin SH, et al: CXCR2 promotes ovarian cancer growth through dysregulated cell cycle, diminished apoptosis, and enhanced angiogenesis. Clin Cancer Res 16: 3875-3886, 2010.

16. Leonard DA, Merhige ME, Williams BA and Greene RS: Elevated expression of the interleukin- 8 receptors CXCR 1 and CXCR2 in peripheral blood cells in obstructive coronary artery disease. Coron Artery Dis 22: 491-496, 2011.

17. Singh S, Wu S, Varney M, Singh AP and Singh RK: CXCR1 and CXCR2 silencing modulates CXCL8-dependent endothelial cell proliferation, migration and capillary-like structure formation. Microvasc Res 82: 318-325, 2011.

18. Wang JP, Hu WM, Wang KS, Yu J, Luo BH, Wu C, Chen ZH, Luo GQ, Liu YW, Liu QL, et al: Expression of C-X-C chemokine receptor types $1 / 2$ in patients with gastric carcinoma: Clinicopathological correlations and significance. Oncol Lett 5: 574-582, 2013.

19. Park SH, Das BB, Casagrande F, Tian Y, Nothnagel HJ, Chu M, Kiefer H, Maier K, De Angelis AA, Marassi FM, et al: Structure of the chemokine receptor CXCR1 in phospholipid bilayers. Nature 491: 779-783, 2012.

20. Jackson AL, Bartz SR, Schelter J, Kobayashi SV, Burchard J, Mao M, Li B, Cavet G and Linsley PS: Expression profiling reveals off-target gene regulation by RNAi. Nat Biotechnol 21: 635-637, 2003.

21. Fedorov Y, Anderson EM, Birmingham A, Reynolds A, Karpilow J, Robinson K, Leake D, Marshall WS and Khvorova A: Off-target effects by siRNA can induce toxic phenotype. RNA 12: 1188-1196, 2006.

22. Li Z, Wang Y, Dong S, Ge C, Xiao Y, Li R, Ma X, Xue Y, Zhang Q, Lv J, et al: Association of CXCR1 and 2 expressions with gastric cancer metastasis in ex vivo and tumor cell invasion in vitro. Cytokine 69: 6-13, 2014.

23. Almhanna K, Strosberg J and Malafa M: Targeting AKT protein kinase in gastric cancer. Anticancer Res 31: 4387-4392, 2011.

24. Sasaki T and Kuniyasu H: Significance of AKT in gastric cancer (Review). Int J Oncol 45: 2187-2192, 2014.

25. Zhang Y, Wang L, Zhang M, Jin M, Bai C and Wang X: Potential mechanism of interleukin-8 production from lung cancer cells: An involvement of EGF-EGFR-PI3K-Akt-Erk pathway. J Cell Physiol 227: 35-43, 2012.

26. Knall C, Worthen GS and Johnson GL: Interleukin 8-stimulated phosphatidylinositol-3-kinase activity regulates the migration of human neutrophils independent of extracellular signal-regulated kinase and p38 mitogen-activated protein kinases. Proc Natl Acad Sci USA 94: 3052-3057, 1997.

27. Correia C, Lee SH, Meng XW, Vincelette ND, Knorr KL, Ding H, Nowakowski GS, Dai H and Kaufmann SH: Emerging understanding of Bcl-2 biology: Implications for neoplastic progression and treatment. Biochim Biophys Acta 1853: 1658-1671, 2015. 
28. Ye X, Guo Y, Zhang Q, Chen W, Hua X, Liu W, Yang Y and Chen G: $\beta$ Klotho suppresses tumor growth in hepatocellular carcinoma by regulating Akt/GSK-3 $\beta /$ cyclin D1 signaling pathway. PLoS One 8: e55615, 2013.

29. Tsai HL, Yeh YS, Chang YT, Yang IP, Lin CH, Kuo CH, Juo SH and Wang JY: Co-existence of cyclin D1 and vascular endothelial growth factor protein expression is a poor prognostic factor for UICC stage I-III colorectal cancer patients after curative resection. J Surg Oncol 107: 148-154, 2013.

30. Venkatakrishnan G, Salgia R and Groopman JE: Chemokine receptors CXCR-1/2 activate mitogen-activated protein kinase via the epidermal growth factor receptor in ovarian cancer cells. J Biol Chem 275: 6868-6875, 2000.

31. Luppi F, Longo AM, de Boer WI, Rabe KF and Hiemstra PS: Interleukin-8 stimulates cell proliferation in non-small cell lung cancer through epidermal growth factor receptor transactivation. Lung Cancer 56: 25-33, 2007.

32. Roomi MW, Monterrey JC, Kalinovsky T, Rath M and Niedzwiecki A: Comparative effects of EGCG, green tea and a nutrient mixture on the patterns of MMP-2 and MMP-9 expression in cancer cell lines. Oncol Rep 24: 747-757, 2010.

33. Roomi MW, Monterrey JC, Kalinovsky T, Rath $M$ and Niedzwiecki A: Patterns of MMP-2 and MMP-9 expression in human cancer cell lines. Oncol Rep 21: 1323-1333, 2009.
34. Sancéau J, Truchet S and Bauvois B: Matrix metalloproteinase-9 silencing by RNA interference triggers the migratory-adhesive switch in Ewing's sarcoma cells. J Biol Chem 278: 36537-36546, 2003.

35. Bergers G, Brekken R, McMahon G, Vu TH, Itoh T, Tamaki K, Tanzawa K, Thorpe P, Itohara S, Werb Z, et al: Matrix metalloproteinase-9 triggers the angiogenic switch during carcinogenesis. Nat Cell Biol 2: 737-744, 2000.

36. Liu X and Chu KM: E-cadherin and gastric cancer: Cause, consequence, and applications. Biomed Res Int 2014: 637308, 2014.

37. Carneiro P, Figueiredo J, Bordeira-Carriço R, Fernandes MS Carvalho J, Oliveira $\mathrm{C}$ and Seruca R: Therapeutic targets associated to E-cadherin dysfunction in gastric cancer. Expert Opin Ther Targets 17: 1187-1201, 2013.

38. Kitadai Y: Cancer-stromal cell interaction and tumor angiogenesis in gastric cancer. Cancer Microenviron 3: 109-116, 2010.

39. Bădescu A, Georgescu CV, Vere CC, Crăitoiu S and Grigore D: Correlations between Her2 oncoprotein, VEGF expression, MVD and clinicopathological parameters in gastric cancer. Rom J Morphol Embryol 53: 997-1005, 2012. 